\title{
Preparation and Properties of Phosphorus Biocomposite Fertilizers Based on the Birch Bark
}

\author{
Evgeniya V. Veprikova, Svetlana A. Kuznetsova, \\ Nikolay V. Chesnokov and Boris N. Kuznetsov* \\ Institute of Chemistry and Chemical Technology SB RAS \\ 50/24 Akademgorodok, Krasnoyarsk, 660036, Russia
}

Received 13.07.2015, received in revised form 30.07.2015, accepted 24.08.2015

The possibility of preparation of phosphorus fertilizers with prolonged time of action by impregnation of porous supports from birch bark and inner birch bark by water solution of $\mathrm{K}_{2} \mathrm{HPO}_{4}$ was shown. Influence of the preparation conditions of the fertilizers on the phosphates leaching by water was studied. The conditions which allow to obtain the fertilizers with minimal phosphates leaching at a long time were determined.

Keywords: biocomposite fertilizer, preparation, $\mathrm{K}_{2} \mathrm{HPO}_{4}$, birch bark, leaching by water, long-time action.

\section{Получение и свойства фосфорных}

\section{биокомпозитных удобрений на основе коры березы}

Е.В. Веприкова, С.А. Кузнецова, Н.В. Чесноков, Б.Н. Кузнецов Институт химии и химической технологии СО РАН Россия, 660036, Красноярск, Академгородок, 50/24

Показана возможность получения фосфорных удобрений пролонгированного действия пропиткой пористых подложек из луба и коры березы водным раствором $\mathrm{K}_{2} \mathrm{HPO}_{4}$. Изучено

(C) Siberian Federal University. All rights reserved

* Corresponding author E-mail address: inm@icct.ru 
влияние условий получения удобрений на вымывание фосфатов водой. Определень условия, позволяющие получать удобрения с минимальным вымыванием фосфатов в течение длительного времени.

Ключевые слова: биокомпозитное удобрение, получение, $\mathrm{K}_{2} \mathrm{HPO}_{4}$, кора березы, вымывание водой, пролонгированное действие.

Получение органоминеральных удобрений на основе древесных материалов является перспективным направлением, поскольку позволяет сократить объемы отходов, вывозимых в отвалы. Применение таких удобрений приводит к улучшению структуры почвы, повышает ее аэрацию, а за счет биоразложения древесной составляющей способствует улучшению гумусного статуса почв $[1,2]$. Отмечено, что органоминеральные системы удобрений помогают уменьшению образования нерастворимых форм питательных элементов в почве, например фосфора [3].

Особое место среди удобрений занимают удобрения пролонгированного действия, способные к длительному выделению питательных элементов в почву. Применение таких удобрений уменьшает вымывание активных элементов грунтовыми водами, что способствует сокращению количеств вносимых в почву традиционных водорастворимых удобрений. В результате снижается уровень загрязнения грунтовых и поверхностных вод в районах земледелия.

Один из способов обеспечения пролонгированного действия удобрений - применение в качестве носителя питательных элементов пористых материалов и материалов с сорбционными или ионообменными свойствами $[4,5]$. Древесные отходы за счет масштабности и доступности сырьевой базы являются перспективным материалом для получения таких носителей. В литературе показана возможность получения азотных и калийных биокомпозитных удобрений с пролонгированным действием на основе пористых подложек из луба и коры березы [6, 7]. Нанесение азота и калия на подложки из луба и коры березы проводили пропиткой растворами мочевины и KCl. Этот способ традиционно используется при получении нанесенных катализаторов. Наряду с простотой выполнения способ позволяет наносить на подложку точно рассчитанное количество активного компонента. Было показано, что повышение температуры сушки оказывает существенное влияние на формирование текстуры калийного биокомпозитного удобрения. Это способствует уменьшению вымывания хлорида калия водой и обеспечивает эффект пролонгированного действия удобрения [7]. Для удаления полифенольных веществ, отрицательно влияющих на рост растений, и развития пористой структуры подложки в этих работах предложено проводить обработку исходного сырья 1-2 \% водными растворами щелочи. В результате такой обработки в подложке сохраняется достаточное количество лигнина, разложение которого в почве поможет повышению содержания гумуса [8].

Цель работы - изучение влияния условий получения биокомпозитных удобрений пропиткой пористых подложек из луба и коры березы раствором $\mathrm{K}_{2} \mathrm{HPO}_{4}$ на вымывание фосфатов водой.

\section{Экспериментальная часть}

Сырьем для получения пористых подложек биокомпозитных удобрений служила кора березы повислой (Betula pendula Roth.), заготовленной в окрестностях г. Красноярска. Кору и 
отделенный от бересты луб сушили до воздушно-сухого состояния (влажность 7,5 $\pm 0,5$ \%) и измельчали на дезинтеграторе марки «Nossen» (Германия). Затем готовили смеси следующего фракционного состава, мас.\%: (0.25-0.50) мм - 23.7; (0.50-1.00) мм - 76.3. Содержание бересты в образце коры березы составляло $(45 \pm 1)$ мас.\%.

Пористые подложки (ПП) из коры и луба березы получали обработкой 1,5\%-ным раствором $\mathrm{NaOH}$ в течение 1 ч при температуре $(80 \pm 5)^{\circ} \mathrm{C}$, гидромодуле 5 и перемешивании с интен-

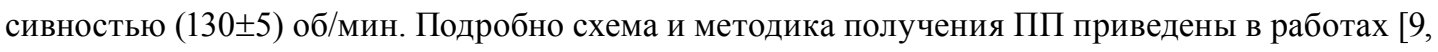
10]. Полученные подложки сушили при $(50 \pm 5)^{\circ} \mathrm{C}$.

Основные стадии получения биокомпозитных удобрений изображены на рис. 1. Биокомпозитные удобрения (БУ) готовили пропиткой подложек водными растворами $\mathrm{K}_{2} \mathrm{HPO}_{4}$ различной концентрации. Количество раствора для пропитки соответствовало влагоемкости подложек, которую определяли согласно ГОСТ 24160-80. Содержание фосфора в БУ варьировали от 3,5 до 5 мас.\%. Пропитанные образцы выдерживали в закрытых бюксах в течение суток при комнатной температуре.

Изотермическую выдержку образцов, пропитанных раствором $\mathrm{K}_{2} \mathrm{HPO}_{4}$, проводили при $100{ }^{\circ} \mathrm{C}$ в течение 2 ч.

Температуру сушки образцов БУ варьировали от 40 до $250{ }^{\circ} \mathrm{C}$. Образцы высушивали до постоянного веса.

Образцы БУ обрабатывали кислотой, пропитывая их растворами $\mathrm{HNO}_{3}$ различной концентрации $(0,05-1,0$ N). Пропитанные образцы выдерживали в закрытых бюксах при комнатной температуре не менее 2 ч и затем сушили при $80-100{ }^{\circ} \mathrm{C}$.

Качество получаемых БУ оценивали по их устойчивости к вымыванию фосфатов в стационарных условиях дистиллированной водой $(\mathrm{pH} 5,4)$ при температуре $(20 \pm 2){ }^{\circ} \mathrm{C}$. Соотношение образцов БУ и воды при изучении вымывания составляло 0,2 г к 50 мл. Продолжительность вымывания фосфатов варьировали от 10 мин до 72 ч.

Концентрацию фосфора в воде определяли методом масс-спектрометрии на приборе ICPMS 7500 Agilent. Проводилось выборочное дублирование определений фосфора фотометрическим методом согласно ГОСТ 200851.2-75. По изменению концентрации фосфора в воде рассчитывали величину вымывания $\mathrm{D}\left(\%\right.$, в пересчете на $\left.\mathrm{P}_{2} \mathrm{O}_{5}\right)$, принимая его исходное количество

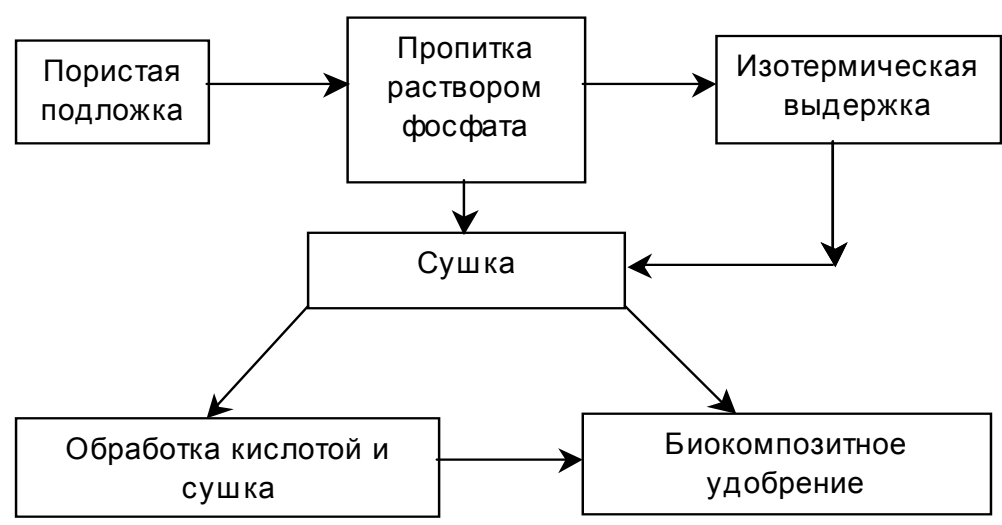

Рис. 1. Схема получения биокомпозитных удобрений на основе подложек из луба и коры березы 
в образце БУ за 100 \%. Параллельно атомно-эмиссионным методом на приборе Analyst-400 определяли количество калия, перешедшего в воду. Величину его вымывания рассчитывали аналогичным образом.

Электронно-микроскопическое исследование образцов биокомпозитных удобрений на основе подложки из луба коры березы проводили на электронном растровом микроскопе ТМ1000 (НІТАСНІ, Япония).

Регистрацию ИК-спектров образцов осуществляли на ИК-Фурье спектрометре Tensor 27 (BRUKER, Германия) в области 4000-400 см-1. Обработку спектральной информации проводили с помощью пакета программ OPUS, версия 5.5. Образцы для получения ИК спектров готовили в виде таблеток в матрице бромистого калия при одинаковых условиях.

\section{Результаты и обсуждение}

Изучено влияние изотермической выдержки, температуры сушки и последующей кислотной обработки образцов БУ, последовательность получения которых приведена на рис. 1. Для оценки влияния условий получения на вымывание фосфатов было выбрано время контакта образцов БУ с водой, равное 10 мин. Этот выбор основан на ранее установленной высокой степени вымывания активного вещества $(\mathrm{KCl})$ с пористых подложек из луба и коры березы в течение первых 5-15 мин [7].

При сопоставлении РЭМ-изображений образцов БУ, полученных пропиткой пористой подложки из березового луба раствором $\mathrm{K}_{2} \mathrm{HPO}_{4}$ (исходное содержание фосфора 3,5 мас.\%) и высушенных при 60 и $200{ }^{\circ} \mathrm{C}$, установлено существенное отличие их морфологии (рис. 2a, б).

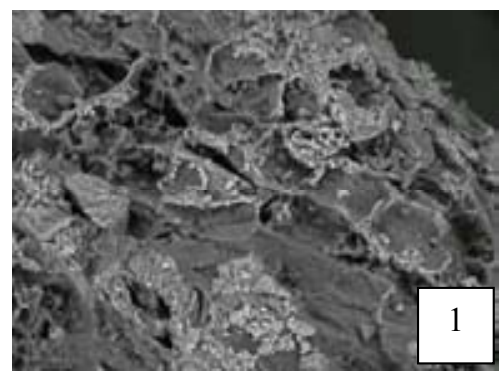

a
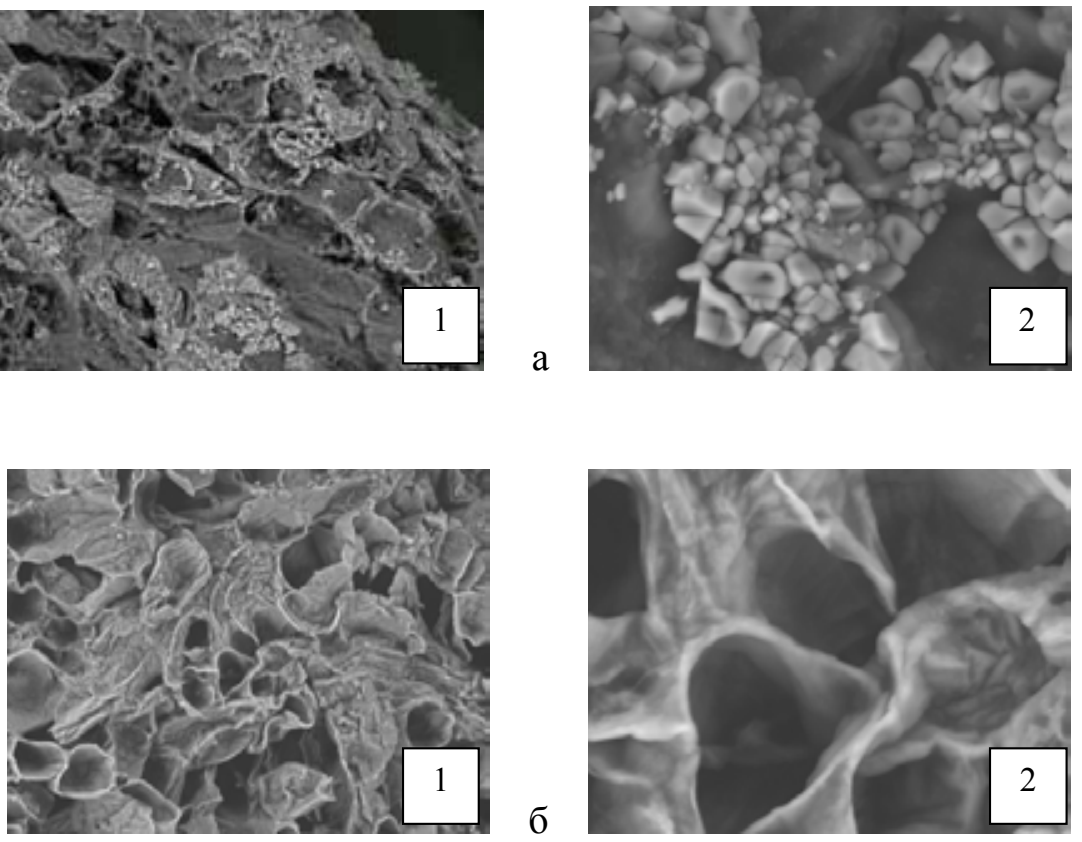

Рис. 2. РЭМ-изображения биокомпозитных удобрений на основе подложки из луба коры березы (исходное содержание фосфора 3,5 мас.\%), полученных при температурах сушки $60{ }^{\circ} \mathrm{C}$ (а) и $200{ }^{\circ} \mathrm{C}($ (б). Увеличение в 1000 раз (1), в 5000 раз (2) 
Так, на поверхности образца БУ, высушенного при $200{ }^{\circ} \mathrm{C}$, отсутствуют кристаллические образования гидрофосфата калия, наблюдаемые при более низкой температуре сушки.

Вероятно, повышение температуры высушивания образца приводит к тому, что фосфаты равномерно распределяются в подложке в виде очень мелких частиц.

Следует отметить, что образцы БУ, высушенные при $200{ }^{\circ} \mathrm{C}$, приобретают более темный цвет по сравнению с образцами, высушенными при 60 и $100{ }^{\circ} \mathrm{C}$. Очевидно, пропитка подложек раствором $\mathrm{K}_{2} \mathrm{HPO}_{4}$, который имеет щелочную реакцию ( $\left.\mathrm{pH} 7,5-8,0\right)$, и последующая сушка приводят к появлению в порах щелочерастворимых веществ коры.

Наблюдаемые изменения структуры поверхности БУ с повышением температуры сушки с 60 до $200{ }^{\circ} \mathrm{C}$ сопровождаются существенным уменьшением вымывания фосфатов водой - в 1,7 раз (рис. 3, кривая 1). Видно, что минимальное вымывание фосфатов (в среднем 45,6 \%) из образцов БУ может быть достигнуто в результате их сушки при температуре $180-220^{\circ} \mathrm{C}$.

Применение изотермической выдержки пропитанных раствором $\mathrm{K}_{2} \mathrm{HPO}_{4}$ образцов БУ при $100{ }^{\circ} \mathrm{C}$ в течение 2 ч до их сушки позволяет уменьшить вымывание из них фосфатов (рис. 3 , кривая 2). При этом наибольший эффект достигается в результате последующего высушивания образцов при $180-220^{\circ} \mathrm{C}$ - вымывание фосфатов водой уменьшается в среднем до $32,3 \%$.

Было установлено, что температура выдержки $\left(100{ }^{\circ} \mathrm{C}\right)$ и ее продолжительность (2 ч) позволяют достичь максимального эффекта, а их увеличение не влияет на вымывание фосфатов водой из образцов БУ.

Сравнительный анализ ИК-спектров образцов БУ, полученных с применением изотермической выдержки и без нее и высушенных при $200^{\circ} \mathrm{C}$, показал схожесть их спектральных картин (рис. 4). В спектрах этих образцов после нанесения $\mathrm{K}_{2} \mathrm{HPO}_{4}$ отмечены изменения в областях поглощения 1100-1050 и 900-500 см с $^{-1}$ за счет появления колебаний связей Р-ОН [11]. При этом не наблюдается сдвига характеристических полос поглощения, соответствующих различным функциональным группам подложки из луба коры березы. Очевидно, что применение изотер-

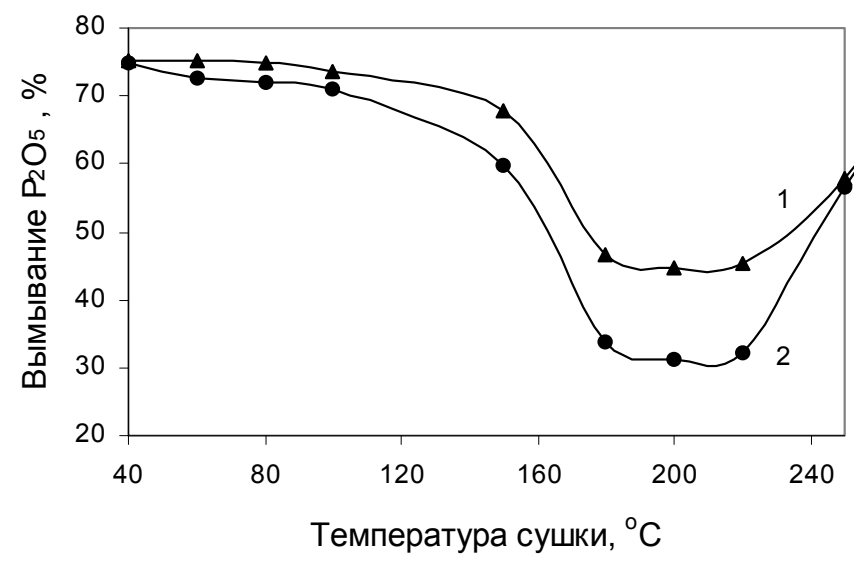

Рис. 3. Влияние температуры сушки биокомпозитных удобрений на основе подложки из луба коры березы на вымывание фосфатов (исходное содержание фосфора 3,5 мас.\%, время вымывания 10 мин): 1 - изотермическая выдержка отсутствует; 2 - использована изотермическая выдержка при $100{ }^{\circ} \mathrm{C}$ в течение 2 ч 


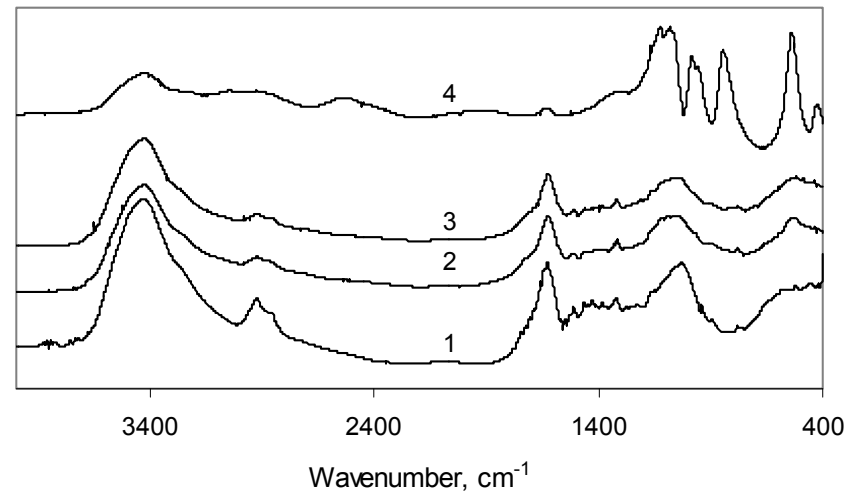

Рис. 4. ИК-спектр биокомпозитных удобрений на основе подложки из луба коры березы (исходное содержание фосфора 3,5 мас.\%): 1 - подложка из луба; 2 и 3 - образцы БУ, полученные без изотермической выдержки и с ее применением соответственно (температура сушки $200{ }^{\circ} \mathrm{C}$ ); $4-\mathrm{K}_{2} \mathrm{HPO}_{4} \times 3 \mathrm{H}_{2} \mathrm{O}$

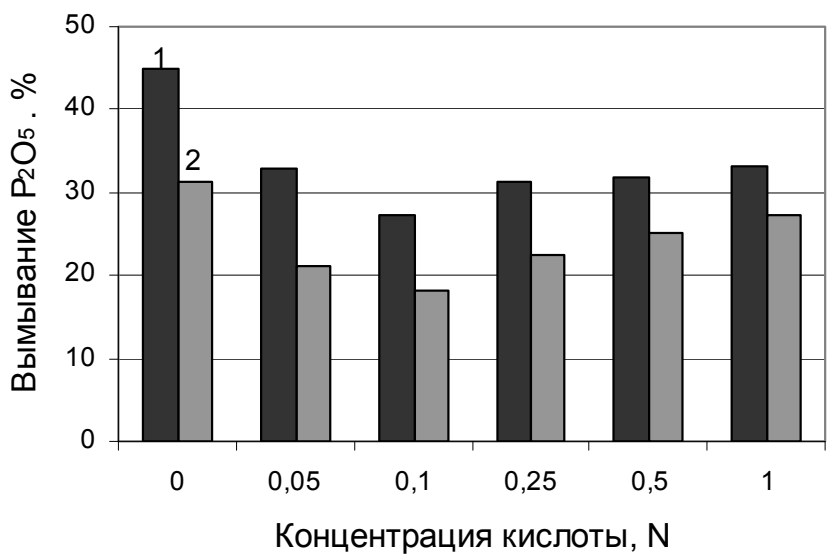

Рис. 5. Влияние концентрации $\mathrm{HNO}_{3}$, применяемой для обработки биокомпозитных удобрений на основе подложки из луба коры березы, на вымывание фосфатов (продолжительность вымывания 10 мин): 1 - изотермическая выдержка отсутствует; 2 - использована изотермическая выдержка при $100{ }^{\circ} \mathrm{C}$ в течение 2 ч

мической выдержки не способствует взаимодействию фосфатов с поверхностными группами подложки из луба.

Вероятной причиной отмеченного влияния изотермической выдержки на способность пористой подложки из луба более прочно удерживать фосфаты может быть взаимодействие $\mathrm{HPO}_{4}{ }^{2-}$ с ее активными центрами, обнаруженными с помощью ЭПР-ионами $\mathrm{Fe}^{3+}$ и $\mathrm{Mn}^{2+}$, обладающими высокой химической активностью [6].

Обработка образцов БУ кислотой согласно схеме, приведенной на рис. 1, также приводит к уменьшению вымывания фосфатов водой (рис. 5). Исследования проводили на образцах, содержащих 3,5 мас.\% фосфора, температура сушки составляла $200{ }^{\circ} \mathrm{C}$. Лучшие результаты достигаются при обработке образцов БУ $0,1 \mathrm{~N}$ раствором $\mathrm{HNO}_{3}$ - вымывание фосфатов составляет 18,3 и 27,2 \% для образцов, полученных с применением изотермической выдержкой и 
без нее соответственно. Образцы, полученные с применением изотермической выдержки, характеризуются большей устойчивостью к вымыванию фосфатов независимо от концентрации кислоты (рис. 5).

Установлено, что в результате кислотной обработки значительно уменьшается цветность водных вытяжек из образцов БУ. Вероятно, подкисление исследуемых образцов приводит к уменьшению растворимости веществ, образовавшихся в процессе пропитки подложки из луба раствором гидрофосфата калия и последующей сушки при $200{ }^{\circ} \mathrm{C}$. Важно отметить, что положительный эффект достигается только в результате обработки кислотой уже высушенных образцов. Подкисление подложек до пропитки раствором гидрофосфата или пропитанных образцов до сушки не оказывает позитивного влияния на их устойчивость к вымыванию фосфатов водой.

В табл. 1 приведены результаты определения вымывания фосфатов водой из образцов БУ с различным исходным содержанием фосфора в течение 72 ч. Образцы были получены при следующих условиях: изотермическая выдержка пропитанных подложек при $100{ }^{\circ} \mathrm{C}$ в течение 2 ч; сушка при $200{ }^{\circ} \mathrm{C}$; обработка $0,1 \mathrm{~N}$ раствором кислоты. Из представленных данных следует, что исследуемые образцы биокомпозитных удобрений обладают способностью к медленному вымыванию фосфатов в течение длительного времени, что определяет эффект пролонгированного действия.

Наибольшей устойчивостью к вымыванию фосфатов обладают образцы БУ, содержащие 3,5-4,0 мас.\% фосфора. Отметим, что БУ на основе подложки из коры березы по вымыванию фосфатов превосходят БУ на основе подложек из луба только в первые 10 мин. В дальнейшем эти образцы мало отличаются по количеству удаляемого водой активного вещества.

Установлено, что по устойчивости к вымыванию фосфатов образцы БУ, содержащие 3,5-4,0 мас.\% фосфора, превосходят промышленное гранулированное удобрение с торговым названием «Суперфосфат простой» (ЗАО КАЗ «Вика», Кемерово). В длительных экспериментах из образца БУ вымывается существенно меньше фосфатов (табл. 1). Важно отметить, что данные образцы БУ характеризуются хорошей устойчивостью к вымыванию калия водой. Так, в течение 10 мин в воду переходит 14,8 и 28,5 \% калия из образцов БУ на основе под-

Таблица 1. Вымывание фосфатов из биокомпозитных удобрений (БУ) на основе луба и коры березы

\begin{tabular}{|c|c|c|c|c|c|}
\hline \multirow{2}{*}{$\begin{array}{c}\text { Материал } \\
\text { подложки БУ }\end{array}$} & \multirow{2}{*}{$\begin{array}{c}\text { Исходное содержание } \\
\text { фосфора, мас.\% }\end{array}$} & \multicolumn{4}{|c|}{ Вымывание фосфатов водой, D \%* } \\
\hline & & 10 мин & 14 & 244 & 724 \\
\hline $\begin{array}{l}\text { Луб коры } \\
\text { березы }\end{array}$ & $\begin{array}{l}3,5 \\
4,0 \\
4,5 \\
5,0\end{array}$ & $\begin{array}{l}18,3 \pm 0,3 \\
18,5 \pm 0,3 \\
22,6 \pm 0,4 \\
27,9 \pm 0,5\end{array}$ & $\begin{array}{c}24,7 \pm 0,5 \\
25,1 \pm 0,5 \\
28,6 \pm 0,8 \\
31,8 \pm 1,1\end{array}$ & $\begin{array}{l}29,5 \pm 0,7 \\
29,8 \pm 0,7 \\
33,2 \pm 1,1 \\
39,7 \pm 1,0\end{array}$ & $\begin{array}{l}33,2 \pm 1,1 \\
34,1 \pm 1,1 \\
36,3 \pm 1,2 \\
44,9 \pm 1,2\end{array}$ \\
\hline Кора березы & $\begin{array}{l}3,5 \\
4,0 \\
4,5 \\
5,0\end{array}$ & $\begin{array}{l}23,7 \pm 0,4 \\
24,2 \pm 0,4 \\
27,5 \pm 0,5 \\
32,7 \pm 0,5\end{array}$ & $\begin{array}{l}26,2 \pm 0,5 \\
26,9 \pm 0,5 \\
31,3 \pm 1,2 \\
34,2 \pm 1,2\end{array}$ & $\begin{array}{l}31,4 \pm 1,2 \\
31,8 \pm 1,2 \\
33,6 \pm 1,1 \\
40,3 \pm 1,5\end{array}$ & $\begin{array}{l}34,1 \pm 1,2 \\
34,5 \pm 1,2 \\
37,5 \pm 1,2 \\
45,6 \pm 1,3\end{array}$ \\
\hline \multicolumn{2}{|c|}{$\begin{array}{l}\text { Суперфосфат простой (ЗАО КАЗ «Вика», } \\
\text { Кемерово)** }\end{array}$} & $19,4 \pm 0,5$ & $32,9 \pm 1,1$ & $52,9 \pm 1,5$ & $82,6 \pm 2,1$ \\
\hline
\end{tabular}

* От исходного содержания фосфора.** Образец сравнения.

$$
-419-
$$


ложек из луба и коры березы соответственно. В течение 24 ч эти значения увеличиваются до 25,3 и 46,2 \%, что существенно меньше вымывания активного компонента в виде хлорида калия [7].

\section{Заключение}

Показана возможность получения фосфорных биокомпозитных удобрений, обладающих повышенной устойчивостью к вымыванию водой путем пропитки пористых подложек из луба и коры березы водным раствором $\mathrm{K}_{2} \mathrm{HPO}_{4}$.

Определены условия получения биокомпозитных удобрений с наибольшей устойчивостью к вымыванию фосфатов: изотермическая выдержка пропитанных образцов при $100{ }^{\circ} \mathrm{C}$ в течение 2 ч; сушка при $200{ }^{\circ} \mathrm{C}$ и последующая обработка $0,1 \mathrm{~N}$ раствором $\mathrm{HNO}_{3}$. Из удобрений, полученных в данных условиях и содержащих 3,5-4 мас.\% фосфора, в течение 72 ч вымывается водой около 35 \% фосфатов, что обеспечивает эффект их пролонгированного действия.

Показано, что для получения удобрений с высокой устойчивостью к вымыванию фосфатов количество наносимого на подложки фосфора не должно превышать 4,0 мас.\%.

Установлено, что по устойчивости к вымыванию фосфатов биокомпозитные удобрения на основе подложек из луба и коры березы превосходят промышленное гранулированное удобрение.

Авторы выражают благодарность сотрудникам Красноярского регионального центра коллективного пользования за проведение электронно-микроскопических исследований и ИК-спектрального анализа.

\section{Список литературы}

1. Беловежец Л.А., Волчатова И.В., Медведева С.А. Перспективные способы переработки вторичного лигноцеллюлозного сырья // Химия растительного сырья. 2010. № 2. С. 5-16. [Belovejest L,A., Volchatova I.V., Medvedeva S.A. The promising methods of recoverable lignocellulosic materials processing. Chemistry of plant raw materials 2010. N 2, P. 5-16. (in Russ.)]

2. Безуглова Л.А. Удобрения и стимуляторы роста. Ростов-на-Дону: Феникс, 2000. 317 c. [Bezuglova L.A. Fertilizers and growth stimulates. Rostov-on-Donu: Feniks, 2000. 317 p. (in Russ.)]

3. Заришняк А.С., Иванина В.В., Калибабчук Т.В. Фосфатный режим чернозема оподзоленного при длительном применении удобрений // Агорхимия. 2014. № 4. C. 20-26. [ Zaryshnyak A.S., Ivanina V.V., Kolibabchuk T.V. Phosphate status of podzolized chernozem under long-term fertilization. Agricultural Chemistry 2014. N.4, P. 20-26.

4. Окуджава Н.Г., Беруашвили Ц.А., Мамукошвили Н.Ш. Получение обогащенного калием природного цеолита двухтемпературным ионообменным методом с использованием морской воды // Сорбционные и хроматографические процессы. 2008. Т. 8 (5). С. 875-880. [Okudjava N.G., Beruashvily C.A., Mamukoshvily N. S. Production of enrich natural zeolite with potassium by too temperature ion-exchanging method with use a sea water. Sorption and chromatographic process 2008. V. 8 (5), P. 875-880. (in Russ.)] 
5. Патент 2502713 РФ. Кожевникова Н.М Торфоцеолитовое удобрение пролонгированного действия, модифицированное фосфатом калия. Опубл. 27.12.2013.[ Patent 2502713 RU. Kojevnikova N.M. The peat -zeolite fertilizer of long - time action modified by potassium phosphate. Publ. Date 27.12.2013 (in Russ.)]

6. Кузнецова С.А., Кузнецов Б.Н., Скурыдина Е.С., Максимов Н.Г., Калачева Г.С., Ульянова О.А., Скворцова Г.П. Синтез и свойства биокомпозитных удобрений на основе мочевины и коры березы // Журнал Сибирского федерального университета. Химия. 2013. Т. 6 (4). С. 380 393.[ Kuznetsova S.A., Kuznetsov B.N., Skurydina E.S., Maksimov N.G., Kalachova G.S, Ulyanova O.A., Skvortsova C.P. Synthesis and properties of biocomposite fertilizers on the basis of urea and birch bark. Journal of Suberian Federal University. Chemistry 2013. V. 6 (4), P. 380-393. (in Russ.)]

7. Веприкова Е.В., Кузнецова С.А., Чесноков Н.В., Кузнецов Б.Н. Изучение вымывания КСl водой из биокомпозитных удобрений на основе коры березы // Журнал Сибирского федерального университета. Химия. 2015. Т. 8 (1). C. 25-34.[ Veprikova E.V., Kuznetsova S.A., Chesnokov N.V., Kuznetsov B.N. Study of KCl Leaching by water from Biocomposite Fertilizers Based on Birch Bark, Journal of Suberian Federal University. Chemistry 2015. V. 8 (1), P. 25-34. (in Russ.)

8. Веприкова Е.В., Кузнецова С.А., Скворцова Г.П., Щипко М.Л. Свойства и применение сорбционных материалов из луба коры березы // Журнал сибирского федерального университета. Химия. 2008. Т. 1 (3). С. 286-292. [Veprikova E.V., Kuznetsova S.A, Skvortsova C.P., Schipko M.L. properties and Application of the Sorption Materials from Outer Birch-Bark. Journal of Suberian Federal University. Chemistry 2008. V. 1 (3), P. 286-292. (in Russ.)

9. Веприкова Е.В., Щипко М.Л., Кузнецова С.А., Кузнецов Б.Н. Получение энтеросорбентов из отходов окорки березы // Химия растительного сырья. 2005. № 1. С. 65-70. [Veprikova E.V., Schipko M.L., Kuznetsova S.A., Kuznetsov B.N. Production of enterosorbents from birch bark wastes. Chemistry of plant raw materials 2005. N. 1, P. 65-70. (in Russ.)]

10. Веприкова Е.В., Кузнецова С.А., Чесноков Н.В., Кузнецов Б.Н. Свойства энтеросорбентов, полученных из автогидролизованной коры березы // Химия в интересах устойчивого развития. 2012. Т. 20 (6). C 673-678. [Veprikova E.V., Kuznetsova S.A., Chesnokov N.V., Kuznetsov B.N. Properties of enterosorbents obtained from auto hydrolyzed birch bark. Chemistry for Sustainable Development 2012. V.20 (6), P 673-678. (in Russ.)]

11. Infrared and Raman characteristic group frequencies: Tables and charts. G.Socrates. John Wiley- Sons, 2004. 347 p. 